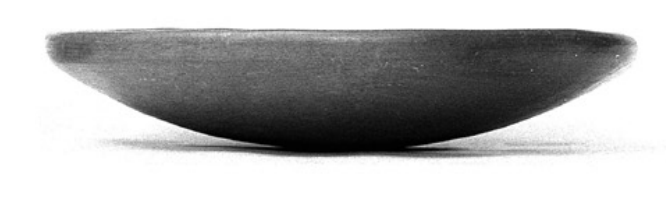

Desarenador para
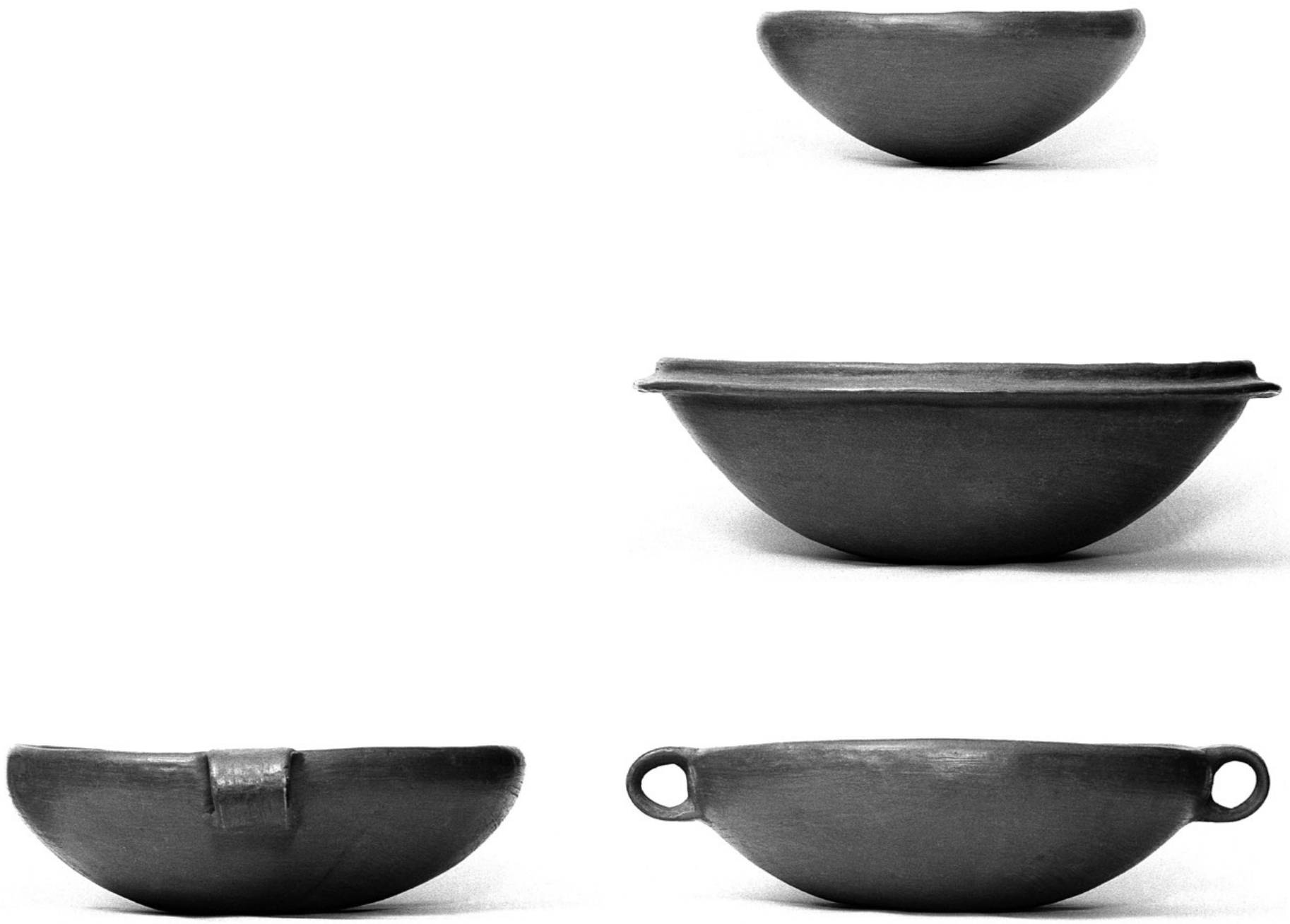

\title{
Piezas de alfarería tradicional de Pomaire
}

Colección de artesanía tradicional chilena

Programa de Artesanía, Pontificia Universidad Católica de Chile

Registro Gonzalo Puga

Fotografía Hugo Lagos

Catalogación María Celina Rodríguez, Carola Fuentes Artesanía Teresa Muñoz
Pomaire debe su origen y nombre al pueblo de indios del siglo XVI, que luego de ser trasladado a distintos lugares, se emplaza en su actual ubicación en 1771. Su tradición alfarera proviene de la época colonial, cuando se fabrican diversas vasijas para los quehaceres de la cocina y grandes tinajas contenedoras de líquidos.

Teresa Muñoz nace en Pomaire en 1915, aprende el oficio de su abuela y su madre. Lo practica desde los 16 años. Trabaja a la antigua, armando la forma manualmente y repitiendo los modelos que hacían sus antepasados.

Obtiene la greda, ya preparada, de la misma zona. Siendo una de las pocas artesanas que mantiene la tradición en la forma de trabajar y en los modelos realizados. 
Pastelera

$15,5 \mathrm{~cm} \times 34 \mathrm{~cm} \varnothing$

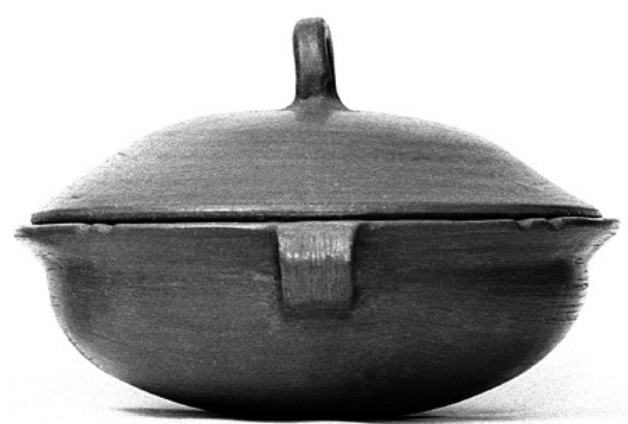

Fuente con tapa

Colorera para

preparar la "color"

$3 \mathrm{~cm} \times 16,5 \mathrm{~cm} \varnothing$

Motera

$12,5 \mathrm{~cm} \times 18,5 \mathrm{~cm} \varnothing$

Motera Grande $29 \mathrm{~cm} \mathrm{x} 41 \mathrm{~cm} \mathrm{\varnothing}$
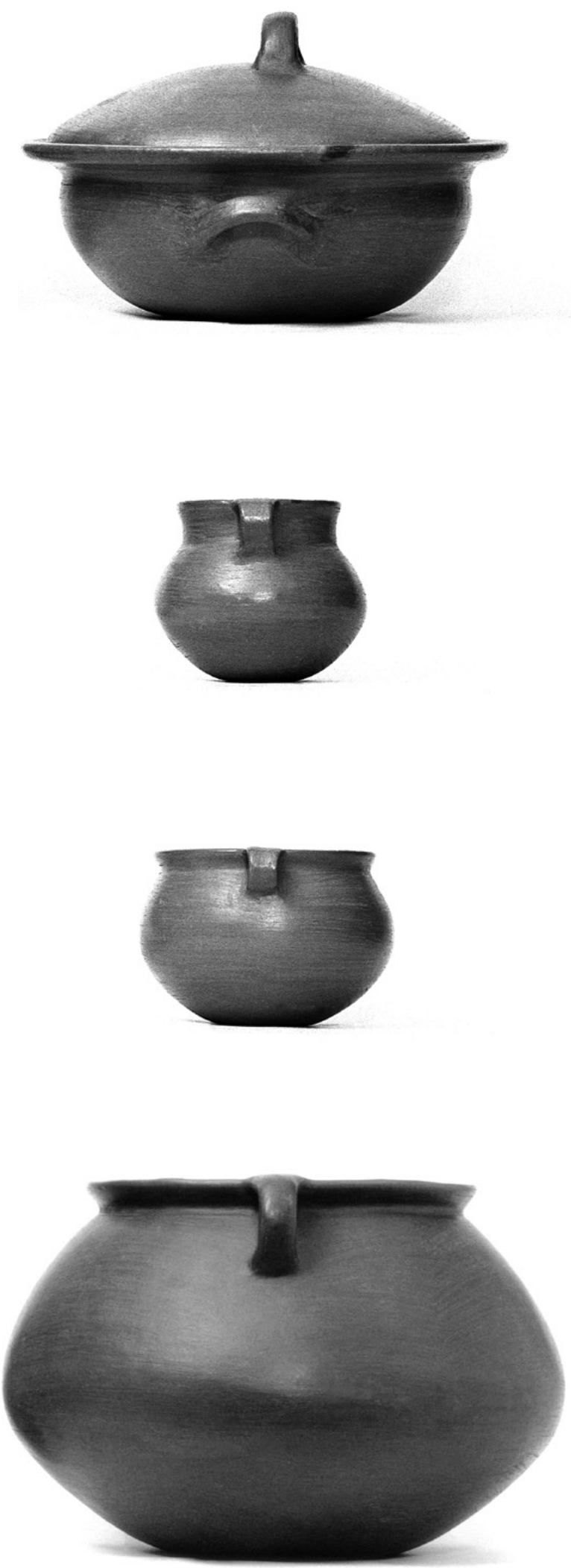
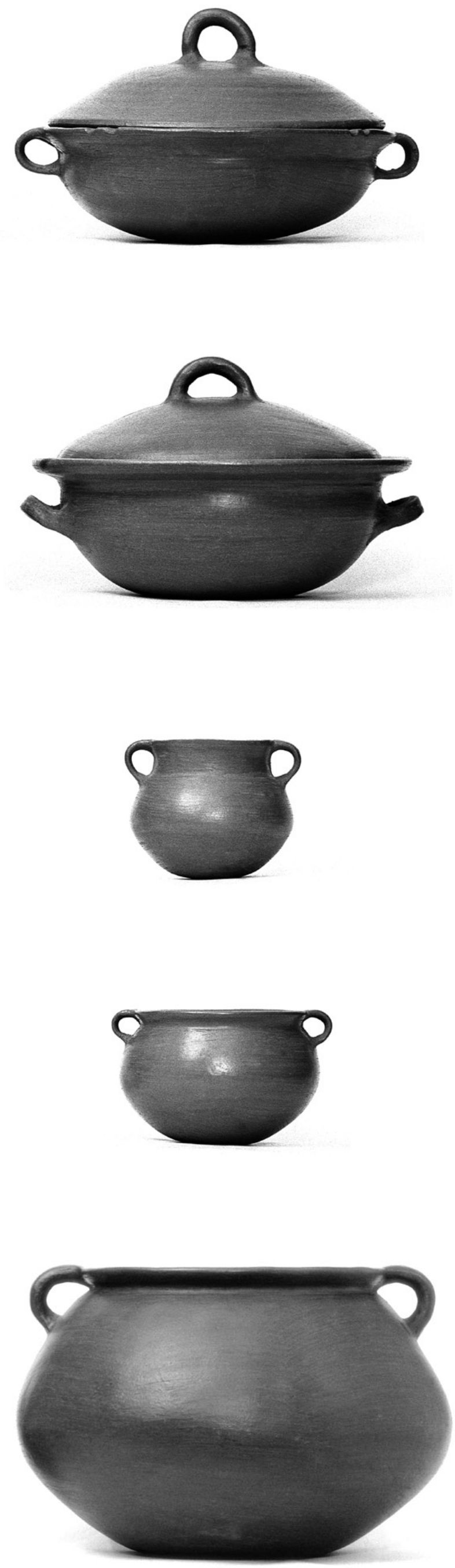

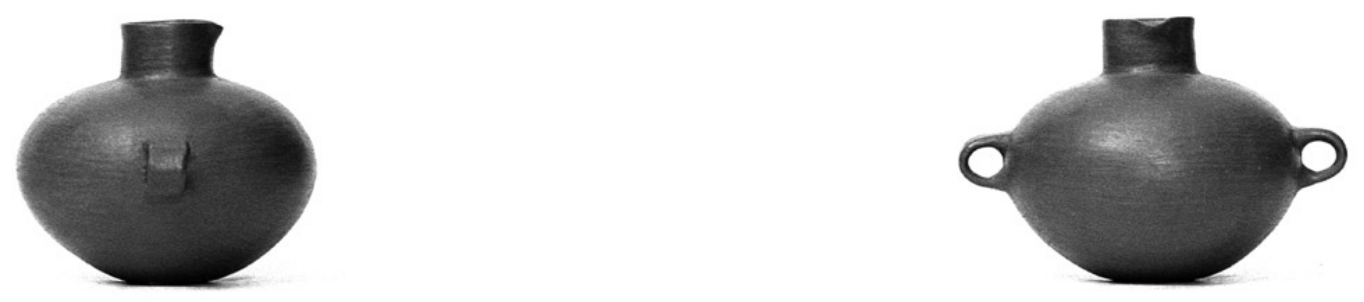

Botijo para guardar

"tesoros"

$5,5 \mathrm{~cm} \times 16 \mathrm{~cm} \varnothing$

ARQ
42
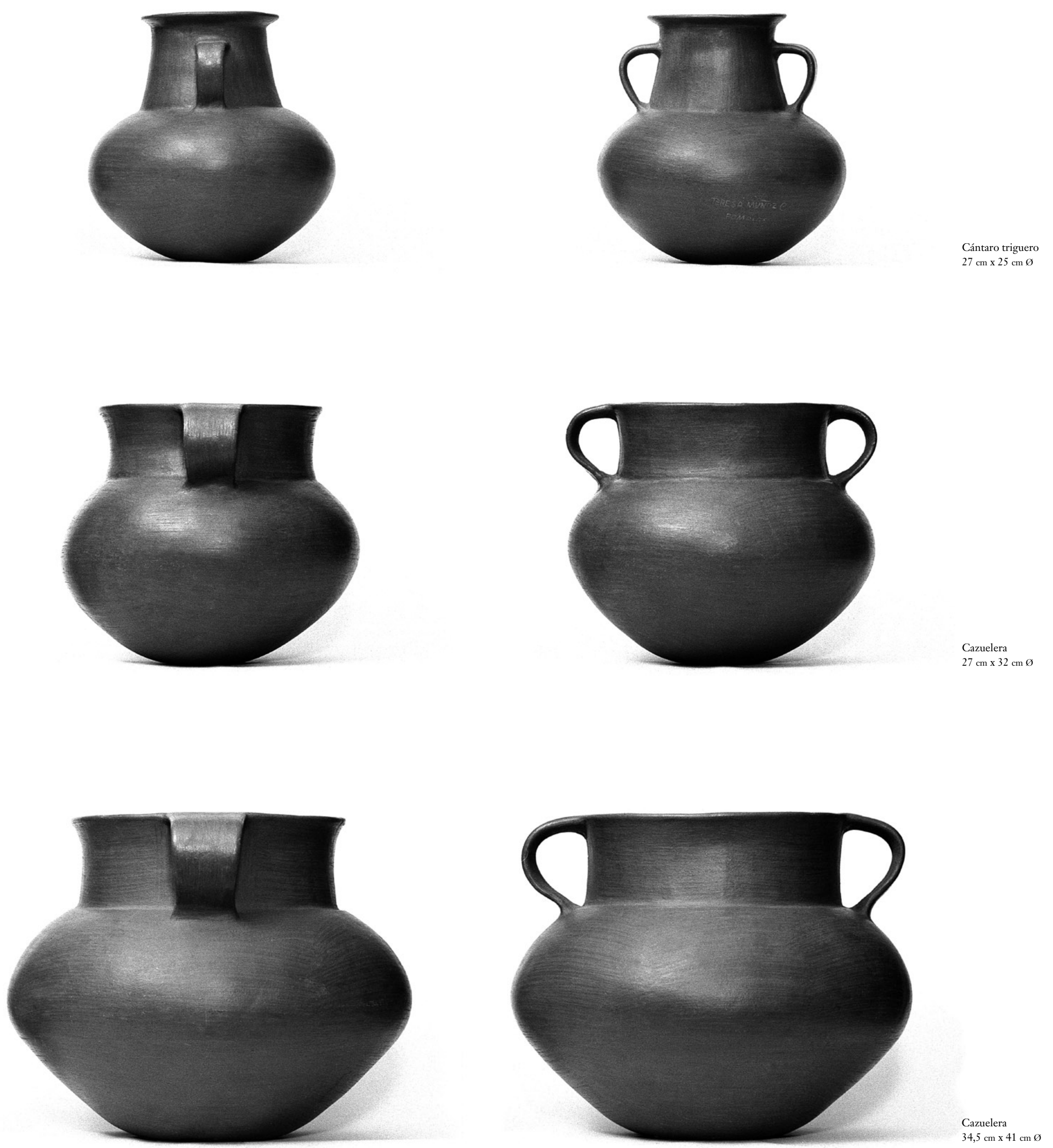

Cántaro triguero

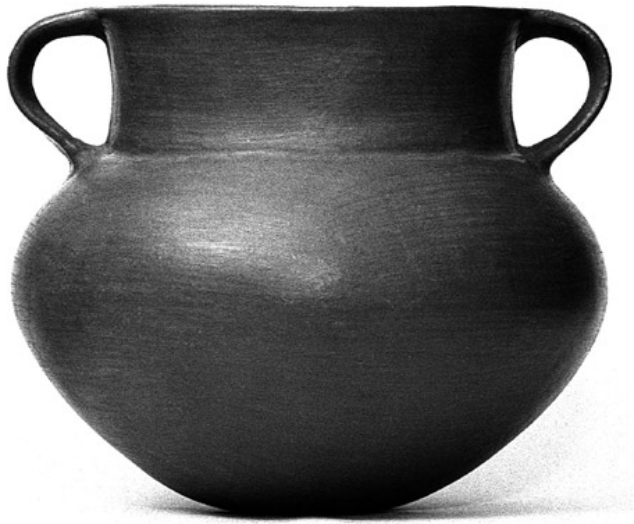

Cazuelera
$27 \mathrm{~cm} \times 32 \mathrm{~cm}$ 
Cántaro de agua

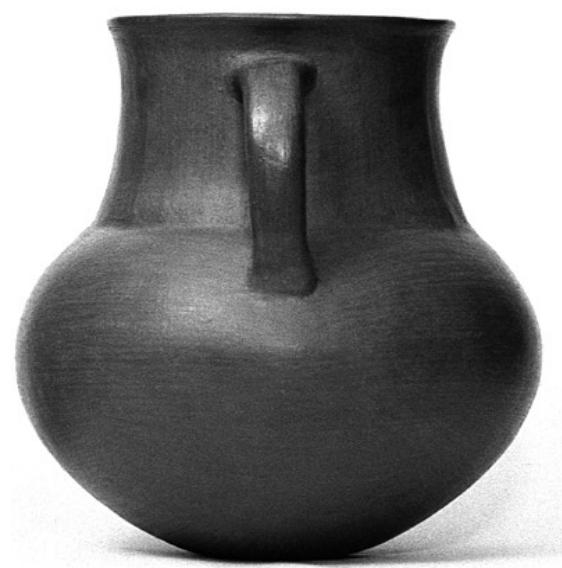

Chichero

$39,5 \mathrm{~cm} \mathrm{x} 41 \mathrm{~cm} \varnothing$

Jarro Lavatorio
$26,5 \mathrm{~cm} \times 18,5 \mathrm{~cm} \varnothing$
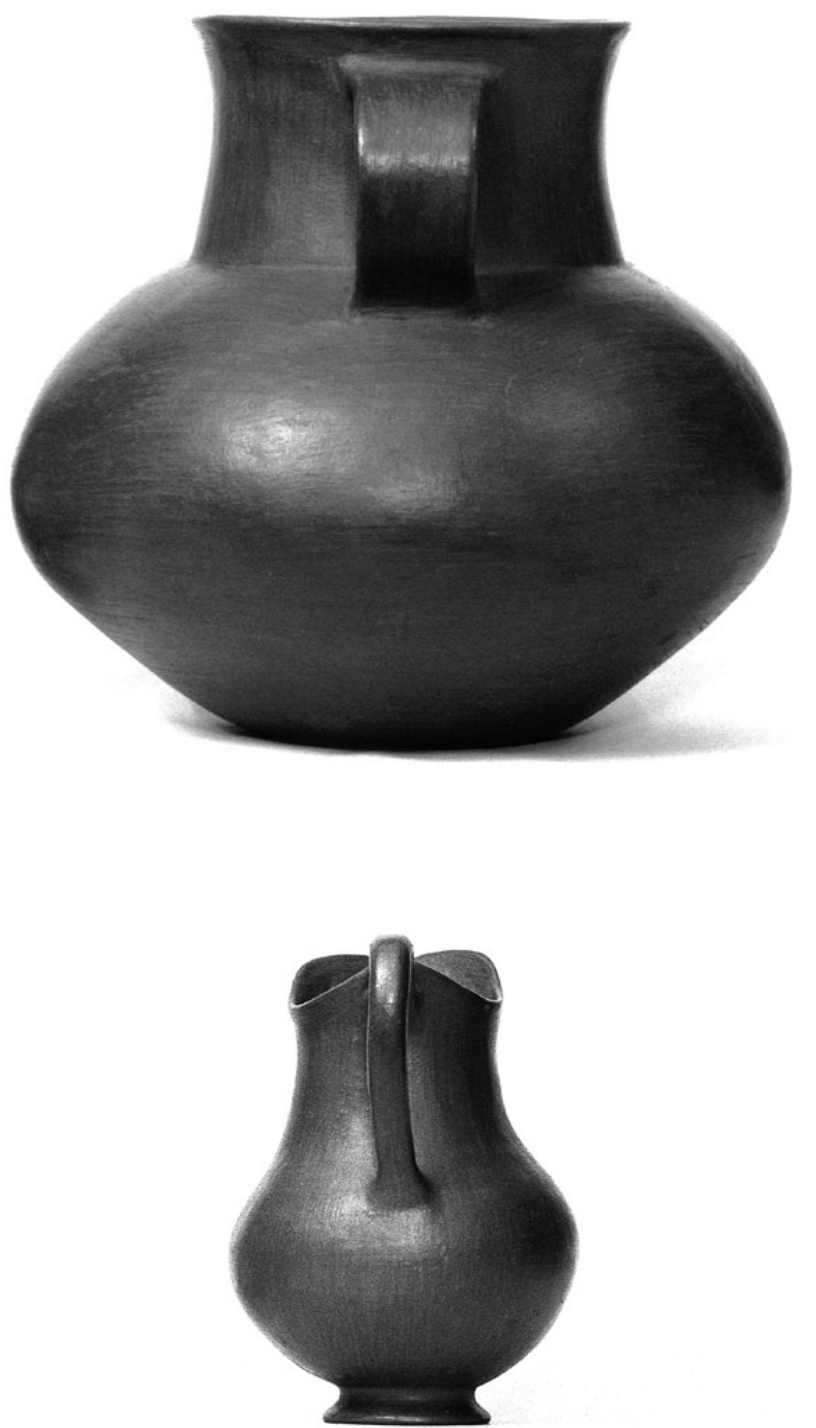

Jarro pato

$17 \mathrm{~cm} \mathrm{x} \mathrm{16,5} \mathrm{cm} \mathrm{x} \mathrm{cm} 18$

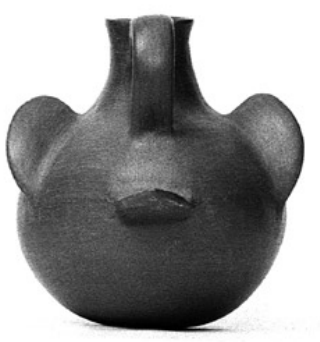

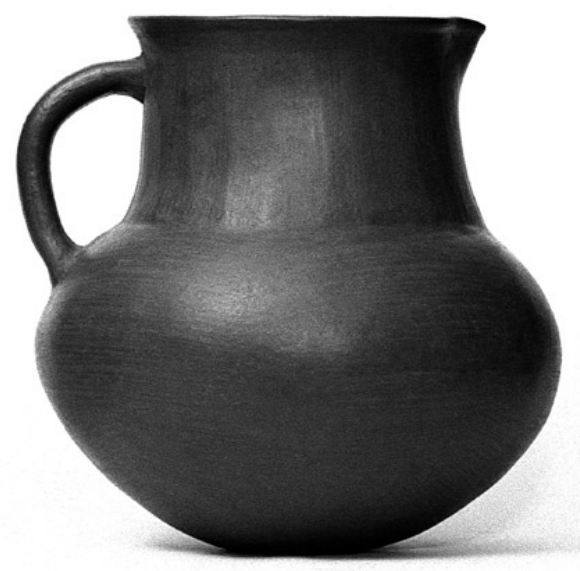

43
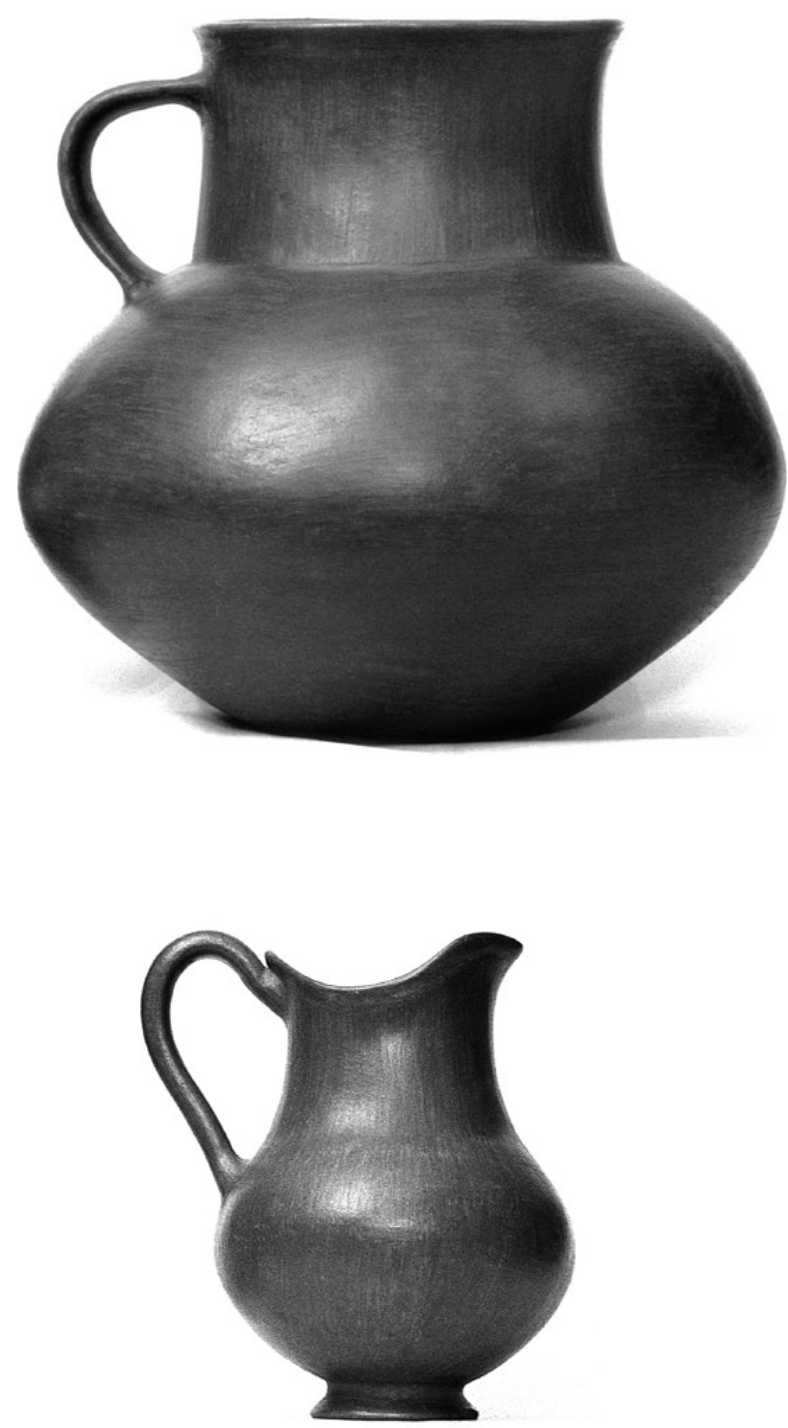